\title{
Quality of life after bone sarcoma surgery around the knee: A long-term follow-up study
}

\author{
W.P. Bekkering PT, PhD, Paediatric Physical Therapist/PostDoc Researcher ${ }^{1,2}$ | \\ J.C. van Egmond-van Dam PT, Paediatric Physical Therapist ${ }^{1}$ | J.A.M. Bramer MD, PhD, \\ Orthopaedic Surgeon $^{2}$ | A. Beishuizen MD, PhD, Paediatric Oncologist ${ }^{3}$ | \\ M. Fiocco PhD, Statistician ${ }^{4}$ | P.D.S. Dijkstra MD, PhD, Orthopaedic Surgeon ${ }^{1}$
}

\author{
${ }^{1}$ Department of Orthopaedics, Rehabilitation \\ and Physical Therapy, Willem-Alexander \\ Children's Hospital, Leiden University \\ Medical Centre, Leiden, The Netherlands \\ ${ }^{2}$ Department of Orthopaedic Surgery, Emma \\ Children's Hospital, Academic Medical \\ Center Amsterdam, University of \\ Amsterdam, Amsterdam, The Netherlands \\ ${ }^{3}$ Department of Paediatric Oncology/ \\ Haematology, Sophia Children's \\ Hospital, Erasmus University Medical \\ Center, Rotterdam, The Netherlands \\ ${ }^{4}$ Department of Medical Statistics/ \\ Bioinformatics, Institute of Mathematics, \\ Leiden University, Leiden, The Netherlands \\ Correspondence \\ W. Peter Bekkering, Child Development \\ \& Exercise Center, Wilhelmina Children's \\ Hospital - Princess Máxima Center for \\ Pediatric Oncology, PO Box 85090, 3508 \\ AB, Utrecht, The Netherlands. \\ Email:w.p.bekkering@prinsesmaximacentrum.nl \\ Funding information \\ Johanna Children Fund, Grant/Award \\ Number: 2003/0111-161; Children Fund \\ Adrian Foundation, Grant/Award Number: \\ 2003/0111; BIO-Children Rehabilitation \\ Fund, Grant/Award Number: 2003/0131-161.
}

It remains unclear if quality of life (QoL) improvements could be expected in young patients after malignant bone tumour surgery after 2 years. To assess the course of QoL over time during a long-term follow-up, malignant bone tumour survivors of a previous short-term study were included. Assessments were done at least 5 years after surgery. QoL was measured with Short-form (SF)-36, TNO-AZL Questionnaire for Adult's Quality of Life (TAAQOL) and Bone tumour (Bt)-DUX. QoL throughout the follow-up was analysed by linear mixed model analysis. From the original cohort of 44 patients; 20 patients were included for this study, 10 males; mean age at surgery 15.1 years and mean follow-up 7.2 years. Twenty-one patients of the initial cohort (47\%) deceased. Fifteen patients (75\%) underwent limb-salvage and five (25\%) ablative surgery. QoL improved significantly during follow-up at Physical Component Summary Scale scale of the SF-36 and TAAQOL and all subscales of the Bt-DUX $(p<.01)$. No significant differences were found between current evaluations and previous evaluations at 2 years after surgery $(p=.41-.98)$. Significant advantages after limb-salvage were seen at the PCS scale of the SF-36 (MD 13.7, $p=.05$ ) and the cosmetic scale of the Bt-DUX (MD 17.7, $p=.04$ ).

KEYWORDS

adolescents, children, leg, malignant bone tumour, prospective, quality of life

\section{1 | INTRODUCTION}

Malignant bone tumours, especially osteosarcoma and Ewing sarcoma account for approximately $6 \%$ of all cancers in children younger than 20 years of age (Damron, Ward, \& Stewart, 2007; SteliarovaFoucher et al., 2004; Stiller, Bielack, Jundt, \& Steliarova-Foucher, 2006). Both bone malignancies have a preference for origination in the metaphysical region of long bones; particularly the knee region (Damron et al., 2007). Since the 1970s, 5 years survival rates in patients with bone sarcoma have increased significantly from less than $20 \%$ to $60 \%-70 \%$; striking changes in surgery for bone tumours accompanied this change in survival due to chemotherapy improvements (Steliarova-Foucher et al., 2004; Stiller et al., 2006). Whereas in the late 1970s amputation was needed in three-quarter of patients, 
due to a combination of improved imaging modalities, nowadays surgical techniques and the responsiveness to chemotherapy led to $85 \%$ or more of the patients to limb-salvage (Abed \& Grimer, 2010; Grimer, 2005; Wafa \& Grimer, 2006).

Although a few reports on quality of life (QoL) are published, most of these studies report QoL levels at one single time point in a wide range of years after surgery and therefore lack information about the duration and extent of the recovery (Eiser \& Grimer, 1999; Nagarajan, Neglia, Clohisy, \& Robison, 2002). Furthermore, only a few studies presented longitudinal assessments of QoL after malignant bone tumour surgery. Limitations of these longitudinal studies were the inclusion of patients with tumour sites in the upper extremity or trunk in addition to patients with tumour sites in the lower extremity. Lower extremity or trunk tumours are less common and have different functional and emotional consequences. Other limitations were a short follow-up period or a confined number of evaluations (Frances, Morris, Arkader, Nikolic, \& Healey, 2007; Han, Wang, \& Bi, 2012; Hinds et al., 2009; Koopman et al., 2005; Liu et al., 2014). Therefore, we evaluated a few years ago QoL levels at six time points of a cohort of children and adolescents under the age of 25 after malignant bone tumour surgery of the lower limb. In this previous study, improvements of QoL levels were reported from surgery up to 24 months thereafter and were most pronounced and significant over the first year after the surgery. Over the second year improvements became smaller and the differences between QoL scores at 1 and 2 years after surgery were mostly non-significant (Bekkering, Vliet Vlieland, Koopman, et al., 2012). However, QoL scores still differed from scores of healthy peers and it remains unclear if further improvements could be expected after this period. Therefore, the aim of this study was to assess the course of QoL over time between 2 and 5 years or more after surgery.

\section{2 | MATERIALS AND METHODS}

\subsection{Study design and patient recruitment}

The study had a prospective and multi-centre design. All consecutive patients who underwent a surgical intervention due to a bone sarcoma around the knee joint in one of three university medical centres in the Netherlands (Leiden University Medical Centre, Academic Medical Center University of Amsterdam and Erasmus University Medical Centre - Sophia Children's Hospital Rotterdam) between January 2004 and January 2008 were invited by their oncologist or orthopaedic surgeon to participate in the previous study. Patients were eligible if they were aged between 8 and 25 years at the time of surgery, the bone sarcoma (osteosarcoma or Ewing sarcoma) was located around the knee and the surgical intervention consisted of limb-salvage or ablative surgery. Patients were excluded if medical conditions other than bone tumour surgery limited their physical activities. At long-term follow-up (more than 5 years after surgery), all survivors of the original study cohort were invited to participate in this study. The Medical Ethics Committee of all three centres approved the extension of the study and all patients signed the informed consent.

\subsection{Assessment methods}

Assessments included; questionnaires concerning QoL which were sent by post and an interview with the investigators (PB and JvE). Patients' baseline socio-demographic (Table 1) and clinical characteristics (age, gender, morphology and the type of surgical intervention) as well as orthopaedic or oncological complications occurring during the follow-up (lung metastases, local recurrence, endoprosthetic or allograft failure, stump infection and type of surgical treatment) were derived from the medical record. Failures of limb-salvage after reconstructive surgery for bone tumours were classified according to Henderson et al. (2014).

Information about the highest level of education, work, marital or family status, sportive activities and sportive and/or social limitations were obtained during a structured interview with the investigators.

\section{3 | Quality of life}

The Short Form (SF)-36 is a generic QoL measure, evaluating eight health concept scales; physical functioning, physical role limitation, bodily pain, general perception of health, vitality, social function, emotional role limitation and mental health. Each scale score ranges from 0 (worst health state) to 100 (best health state). These eight scales can be converted into a Physical Component Summary Scale (SF36-PCS) and a Mental Component Summary scale (SF36-MCS). Scores above and below the mean score 50 (standard deviation $S D=10$ ) indicating above and below average QoL respectively (Aaronson et al., 1998; Ware et al., 1995, 1998).

The age specific TNO-AZL Questionnaire for Adult's Quality of Life (TAAQOL) for persons of 16 years and older consist of 12 health concept scales: gross motor functioning, fine motor functioning, cognition, sleep, pain, social contacts, daily activities, sex, vitality, happiness, depressive mood and anger (Kamphuis et al., 2002) The domain scores of the TAAQOL can be converted into a Mental Component Summary Scale (TAAQOL-MCS) and a Physical Component Summary Scale (TAAQOL-PCS) (Bekkering, Vliet Vlieland, Koopman, et al., 2012; Maurice-Stam, Grootenhuis, Caron, \& Last, 2007; MauriceStam et al., 2008; Ware et al., 1995). Scores above and below the mean score of $50(S D=10)$ indicating above and below average QoL respectively. In patients younger than 16 years during the initial study the Mental and Physical Component Summary scale scores of the TNO-AZL Children's Quality of Life questionnaire (TACQOL) were used (Verrips, Vogels, den Ouden, Paneth, \& Verloove-Vanhorick, 2000; Vogels et al., 1998).

The Bone tumour (Bt)-DUX is a disease specific questionnaire for QoL assessment in patients after malignant bone cancer surgery of the leg (Bekkering et al., 2009; Bekkering et al. 2013) comprising 20 items within four domains (social, emotional, cosmetically and physical). The scoring of the items is done by abstract faces with varying expressions, 
TABLE 1 Socio-demographic and disease characteristics of all patients in study and patients who completed the full study

\begin{tabular}{|c|c|c|c|c|}
\hline & All patients $(N=44)$ & Limb-salvage $(N=27)$ & Ablative surgery $(N=17)$ & $\begin{array}{l}\text { Long-term } \\
\text { follow-up }(N=20)\end{array}$ \\
\hline \multicolumn{5}{|l|}{ Gender, N (\%) } \\
\hline Male & $27(61)$ & $18(67)$ & $9(53)$ & $10(50)$ \\
\hline Age at surgery, years (SD) & $14.9(4.8)$ & $15.1(5.1)$ & $14.5(4.4)$ & $15.1(3.9)$ \\
\hline Duration follow-up, years (SD) & & & & $7.2(1.1)$ \\
\hline \multicolumn{5}{|l|}{ Type of surgery, $N(\%)$} \\
\hline Allograft & $8(18)$ & & & $6(30)$ \\
\hline Prosthesis & $19(43)$ & & & $9(45)$ \\
\hline Osteosarcoma & $39(89)$ & $25(85)$ & $16(94)$ & $15(75)$ \\
\hline Ewing's sarcoma & $5(11)$ & $4(15)$ & $1(6)$ & $5(25)$ \\
\hline \multicolumn{5}{|l|}{ Localisation, $N(\%)$} \\
\hline Distal femur & $32(73)$ & $20(74)$ & $12(70)$ & $11(55)$ \\
\hline Proximal tibia & $12(27)$ & $7(26)$ & $5(30)$ & $9(45)$ \\
\hline \multicolumn{5}{|l|}{ Progression of disease, $N(\%)$} \\
\hline Lung metastases at diagnosis & $8(18)$ & $5(19)$ & $3(18)$ & $0(0)$ \\
\hline Lung metastases during follow-up & $24(55)$ & $11(41)$ & $13(77)$ & $1(5)$ \\
\hline Local recurrence & $10(23)$ & $7(26)$ & $3(18)$ & $0(0)$ \\
\hline
\end{tabular}

ranging from very happy (score 1) to sad (score 5). The raw item scores are converted into total and domain scores, ranging from 0 to 100 , with the highest scores indicating better QoL.

\subsection{Statistical analysis}

All analyses were performed with IBM-SPSS statistics 20.0 for Windows (SPSS Inc., Chicago, IL, USA). To analyse QoL levels over time a linear mixed model was used, with subject as random variable. Estimated marginal means with their corresponding standard errors are computed at each time point for the two groups of patients: ablative limb and salvage surgery, as well as for the full sample. The level of significance was set at $p<.05$ in all statistical analysis.

\section{3 | RESULTS}

\section{1 | Patients}

Twenty patients from the original cohort of 44 patients were included for reassessment at more than 5 years after surgery (mean 7.2 years, range 5.1-8.8 years) for this study. Ten of them were males and 10 females, mean age at surgery was 15.1 years (SD 3.9), age at last evaluation was 22.3 years (SD 4.0) and follow-up duration was 7.2 years (SD 1.1). Fifteen patients (75\%) underwent limb-salvage and 5 (25\%) ablative surgery. All patients were treated conform EURAMOS-, EORTC/EOI-80931 or Euro-EWING protocol.

The loss of patients during the study is shown in Figure 1. Twentyone patients of the original cohort died of disease (DOD) and one patient was excluded for social/emotional problems before the current evaluation started. From the remaining 22 patients; two patients refused for unknown reasons to participate in the extension of the study. The 5 years survival of our cohort was $55 \%$. More patients died within 5 years in the ablative surgery group (69\% against $37 \%$ in the limb-salvage group), osteosarcoma patients (62\% against $0 \%$ in Ewing sarcoma patients) and in patients with in the distal femur localised bone tumours (66\% against $25 \%$ in the proximal tibia). The KaplanMeier survival curve of our 44 children and adolescents after limbsalvage and ablative surgery is shown at Figure 2.

From the 20 patients who survived and agreed to participate in this study, one patient had progression of disease during the 5 years follow-up (alive with disease AWD) and was treated several times with thoracic surgery due to lung metastases. 


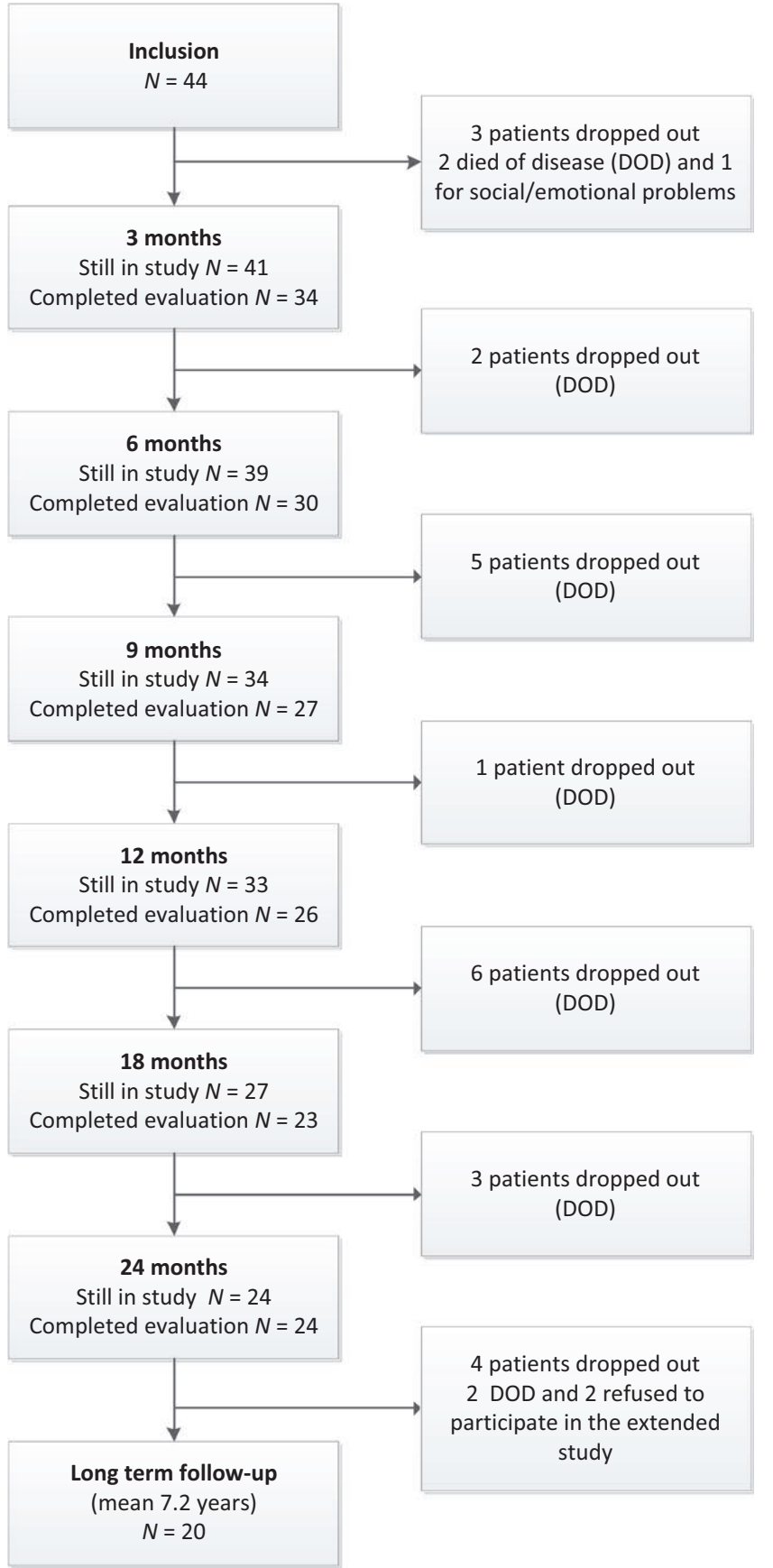

FIGURE 1 Flow chart; showing the number of patients in the study and those who dropped out at different stages of the study

Surgery-related complications were quite common among our survivors, among the limb-salvage patients $67 \%$ and in ablative surgery $20 \%$ encountered complications. However, these differences were not significant according to the Fisher's Exact Test. Three patients with an allograft (50\%) encountered problems; one due to a delayed graft-host union (type 2 failure according to Henderson), one due to fracture of the allograft (type 3 ) and one due to infection (type 4). Seven patients with an endoprosthesis (78\%) encountered problems; two due to aseptic loosening (type 2 failure), four due to structural failure (type 3) resulting into prosthesis revision and one due to infection (type 4)

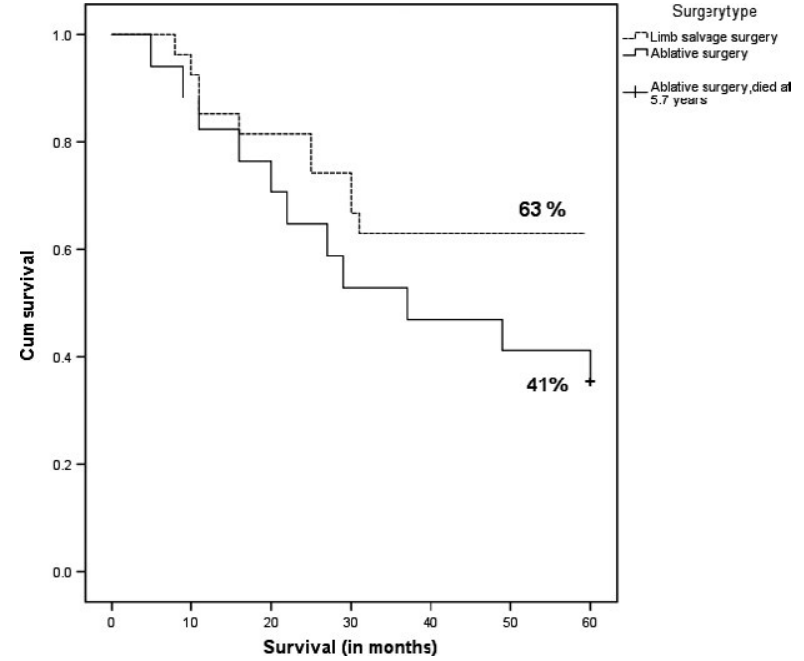

FIGURE 2 Kaplan-Meier survival curve for children and adolescents after limb-salvage and ablative surgery

TABLE 2 Estimated marginal mean scores (standard error in brackets) and differences between evaluations at 2 years after surgery versus long-term (more than 5 years) follow-up

\begin{tabular}{|c|cccc|}
\hline & 2 years & Long-term & Mean difference (CI) & $p$ \\
\hline SF-36 & & & & \\
\hline PCS & $42.3(3.1)$ & $39.2(3.1)$ & $3.1(-4.4$ to 10.6$)$ & .41 \\
\hline MCS & $56.6(2.3)$ & $57.5(2.3)$ & $-0.9(-6.3$ to 4.4$)$ & .74 \\
\hline TAAQOL & & & & \\
\hline PCS & $43.8(4.1)$ & $42.3(3.2)$ & $1.5(-5.5$ to 8.4$)$ & .68 \\
\hline MCS & $52.3(2.1)$ & $50.6(2.3)$ & $1.7(-2.9$ to 6.2$)$ & .47 \\
\hline Bt-DUX & & & & \\
\hline Emotional & $79.9(3.4)$ & $77.5(3.6)$ & $2.3(-5.9$ to 10.5) & .57 \\
\hline Social & $82.8(3.5)$ & $83.2(3.7)$ & $-0.3(-8.9$ to 8.2$)$ & .94 \\
\hline Cosmetic & $77.7(3.5)$ & $77.3(3.7)$ & $-0.1(-10.5$ to 10.2) & .98 \\
\hline Physical & $57.3(4.3)$ & $57.4(4.6)$ & $-0.1(-10.5$ to 10.2$)$ & .98 \\
\hline Total & $74.4(2.9)$ & $73.8(3.2)$ & $0.6(-6.6$ to 7.9$)$ & .86 \\
\hline
\end{tabular}

PCS, Physical component summary score; MCS, Mental component summary score; $\mathrm{Cl}, 95 \%$ Confidence interval.

(Henderson et al., 2014). One amputation patient (20\%) encountered problems due to stump infection.

At long-term follow-up, 19 of the remaining patients (95\%) were active with study, job or both, one patient was full-time mother.

The educational level of 11 (55\%) of our patients has been low (up to and including lower technical and vocational training); medium (up to and including secondary technical and vocational training) in seven (35\%) patients; and high (up to and including higher technical and vocational training and university) in two (10\%) patients.

Four (20\%) of our patients reported limitations in work or study due to the surgical intervention, seven patients (35\%) reported social limitations and 10 patients (50\%) reported limitations in their sportive 
abilities. Eleven patients (55\%) were active in sports, mainly individual and all low intensive sports like fitness, swimming or biking (7 patients choose another sport due to the surgery). Eleven patients (55\%) were still living with their parents; 10 were involved in a relationship and four had one or more children.

\section{2 | Long-term versus short-term follow-up}

Table 2 displays the estimated marginal mean QoL scores and the differences between the short-time evaluation at 24 months and the long-term evaluation at a minimum of 5 years after surgery. Differences between the QoL measures at long-term follow-up and the previous measurement at 24 months since surgery were very small and not significant.

\section{3 | Limb-salvage versus ablative surgery}

Table 3 displays the estimated marginal mean QoL scores and the differences between patients after limb-salvage and ablative surgery. Patients after limb-salvage surgery scored predominantly better than patients after ablative surgery, these differences were significant for the PCS of the SF36 and the cosmetic scale of the Bt-DUX

\subsection{Course over time since surgery}

Table 4 and Figure 3 displays the changes over time since surgery. The Estimated Marginal Mean scores of the PCS of SF-36 and TAAQOL and all Bt-DUX scores improved significantly over time since surgery as evaluated with a Linear Mixed Model analyses. However, these improvements were most pronounced during the first year after the surgery, levelled off during the second year and were nearly absent between follow-up at 24 months and the followup in this study.
During follow-up, the SF-36 and TAAQOL Mental Component Summary scale (MCS) scores from our patients were consistently above the mean of their healthy peers; however, these differences were non-significant.

\subsection{Course over time for the different surgical groups}

Table 4 report the changes over time since surgery for the different surgery groups separately. Estimated Marginal Mean scores varied strongly over time since surgery and among all QoL subscales. However, the differences between the surgery groups were not significant.

\section{4 | DISCUSSION}

This article reports the results of a reassessment of QoL levels of a prospective cohort of bone sarcoma patients long-term after surgery of the leg.

Due to DOD only half of the original cohort of 44 patients could be invited for this extended study, limiting the generalisability of the results of this study. The 5 years survival rate of $55 \%$ in our study is comparable with other studies among young patients after lower extremity bone tumours (Bacci et al., 2006; Damron et al., 2007; Hagleitner et al., 2011).

During the 5 years follow-up, patients after endoprosthetic replacement encountered more surgery-related complications than patients after ablative surgery. Besides endoprosthetic failures like infection or loosening were structural failures of the endoprosthesis the most frequent failures within the follow-up period, and compared with other studies reporting an estimated 5- and 8-year implant survival rates of $68 \%$ and $58 \%$ respectively (Capanna et al., 2015; Pala et al., 2013). However, our study consists of a small cohort of predominantly
TABLE 3 Estimated marginal mean scores (standard error in brackets) and differences between limb-salvage versus ablative surgery patients at more than 5 years follow-up

\begin{tabular}{|c|c|c|c|c|}
\hline & Limb-salvage $(N=15)$ & Ablative surgery $(N=5)$ & Mean difference $(\mathrm{Cl})$ & $p$ \\
\hline \multicolumn{5}{|l|}{ SF-36 } \\
\hline PCS & $43.0(3.5)$ & $29.3(5.9)$ & $13.7(0.2-27.2)$ & $.05^{*}$ \\
\hline MCS & $56.7(2.8)$ & $60.0(4.5)$ & $-3.0(-13.4$ to 7.4$)$ & .74 \\
\hline \multicolumn{5}{|l|}{ TAAQOL } \\
\hline PCS & 43.9 (3.9) & $35.4(6.1)$ & $8.5(-5.8$ to 22.8$)$ & .24 \\
\hline MCS & $49.7(2.8)$ & $53.2(4.2)$ & $-3.5(-13.5$ to 6.5$)$ & .49 \\
\hline \multicolumn{5}{|l|}{ Bt-DUX } \\
\hline Emotional & $79.7(4.3)$ & $72.5(6.9)$ & 7.1 (-8.8 to 23.1$)$ & .38 \\
\hline Social & $85.3(4.3)$ & $75.9(7.1)$ & 9.4 (-6.9 to 25.8$)$ & .26 \\
\hline Cosmetic & $81.2(4.4)$ & $63.4(7.1)$ & $17.7(1.3-34.2)$ & $.04^{*}$ \\
\hline Physical & $56.2(5.3)$ & $55.9(8.7)$ & 0.4 (-19.8 to 20.6$)$ & .97 \\
\hline Total & 75.9 (3.8) & $66.7(6.1)$ & $9.2(-5.1$ to 23.5$)$ & .21 \\
\hline
\end{tabular}

PCS, Physical component summary score; MCS, Mental component summary score; $\mathrm{Cl}, 95 \%$ confidence interval.

*Significant at the .05 level. 
TAB LE 4 Estimated marginal mean scores (standard error) of quality of life measures and difference over time for the whole group and between the surgery groups

\begin{tabular}{|c|c|c|c|c|c|c|c|c|c|}
\hline & \multicolumn{7}{|c|}{ Time points (months) } & \multicolumn{2}{|l|}{$p$-value } \\
\hline & $\frac{3}{N=34}$ & $\frac{6}{N=30}$ & $\frac{9}{N=27}$ & $\frac{12}{N=26}$ & $\frac{18}{N=23}$ & $\frac{24}{N=24}$ & $\frac{60+}{N=20}$ & CS & CS*surgery \\
\hline \multicolumn{10}{|l|}{ SF-36 } \\
\hline \multicolumn{10}{|l|}{ PCS } \\
\hline AS & $3.4(4.0)$ & $17.1(4.0)$ & $31.5(4.5)$ & $28.6(4.3)$ & $37.2(4.3)$ & $40.0(5.0)$ & $29.3(5.9)$ & $<.001^{*}$ & .09 \\
\hline \multicolumn{10}{|l|}{ MCS } \\
\hline ALL & $56.7(2.1)$ & $61.0(2.0)$ & $59.9(2.1)$ & $58.4(2.1)$ & $57.2(2.2)$ & $56.6(2.3)$ & $57.5(2.3$ & \multirow[t]{2}{*}{.45} & \multirow[t]{2}{*}{.71} \\
\hline LS & $57.0(2.8)$ & $59.4(2.6)$ & $59.7(2.8)$ & $56.8(2.7)$ & $59.0(3.0)$ & $55.8(2.9)$ & $56.7(2.8)$ & & \\
\hline ALL & $11.5(2.7)$ & $22.9(2.8)$ & $30.1(2.9)$ & $38.6(2.8)$ & $42.9(3.0)$ & $43.8(4.1)$ & $42.3(3.2)$ & \multirow[t]{3}{*}{$<.001^{*}$} & \multirow[t]{3}{*}{.25} \\
\hline LS & $11.2(3.6)$ & $17.9(3.7)$ & $29.8(3.9)$ & $37.6(3.7)$ & $41.6(4.1)$ & $43.8(3.8)$ & $43.9(3.9)$ & & \\
\hline AS & $12.2(4.2)$ & $29.3(4.2)$ & $30.7(4.4)$ & $40.0(4.4)$ & $44.5(4.5)$ & $43.3(4.9)$ & $35.4(6.1)$ & & \\
\hline \multicolumn{10}{|l|}{ MCS } \\
\hline ALL & $48.5(1.9)$ & $53.1(2.0)$ & $51.3(2.1)$ & $53.3(2.0)$ & $53.6(2.1)$ & $52.3(2.1)$ & $50.6(2.3)$ & \multirow[t]{3}{*}{.5} & \multirow[t]{3}{*}{.51} \\
\hline LS & $50.2(2.6)$ & $51.5(2.7)$ & $51.5(2.8)$ & $53.3(2.7)$ & $54.1(2.9)$ & 51.1 & $49.7(2.8)$ & & \\
\hline AS & $46.4(2.7)$ & $54.9(3.0)$ & $51.2(3.2)$ & $53.1(3.2)$ & $53.0(3.2)$ & $54.5(3.5)$ & $53.2(4.2)$ & & \\
\hline \multicolumn{10}{|l|}{ Bt-DUX } \\
\hline
\end{tabular}

PCS, Physical component summary score; MCS, Mental component summary score; ALL, All patients; LS, Limb-salvage; AS, Ablative surgery; 60+, longterm follow-up at more than 5 years after surgery; CS, Change score (linearly independent pair wise comparisons among the estimated marginal means); CS*surgery, Change score in relation to the different surgical interventions (linearly independent pair wise comparisons among the estimated marginal means).

*Significant at the .05 level.

young patients, possibly loading their endoprosthesis more intensively as elderly patients in other studies by working, studying or leisure activities.

In comparison with healthy peers, our patients report significantly lower QoL scores regarding the physical QoL domains and advantageous scores at the mental QoL domains. These findings are in line with previous studies among patients with bone sarcoma of the leg that consistently demonstrated lower QoL scores within domains associated with physical functioning and similar scores within domains associated with mental functioning in patients as compared to healthy peers (Eiser, Darlington, Stride, \& Grimer, 2001; Eiser \& Grimer, 1999; Hoffman, Saltzman, \& Buckwalter, 2002; Koopman et al., 2005; Rodl et al., 2001; Veenstra, Sprangers, van der Eyken, \& Taminiau, 2000).

It is assumed that the response shift phenomenon plays a role in these positive mental QoL outcome scores. Response shift is defined as a change in the self-report as a result of: a change in internal standards (recalibration), a change in values (reprioritisation) or a change in the sense of QoL itself (reconceptualisation). Response shifts may be seen as a desirable result of the ability of humans confronted with a life-threatening or chronic disease to adapt to changing circumstances to make life bearable (Breetvelt \& van Dam, 1991; Jansen, Stiggelbout, Nooij, Noordijk, \& Kievit, 2000). The mental QoL status of our patients remained favourable in comparison with healthy peers from the first evaluation at 3 months after surgery until the last evaluation with absence of deterioration due to normalisation or the experience of functional limitations and surgery-related complications.

Differences in QoL scores of patients after limb-salvage and ablative surgery are small and are predominantly non-significantly different from each other. These results are in line with previous studies reporting small and inconsistent differences between the surgery groups. Some of these 


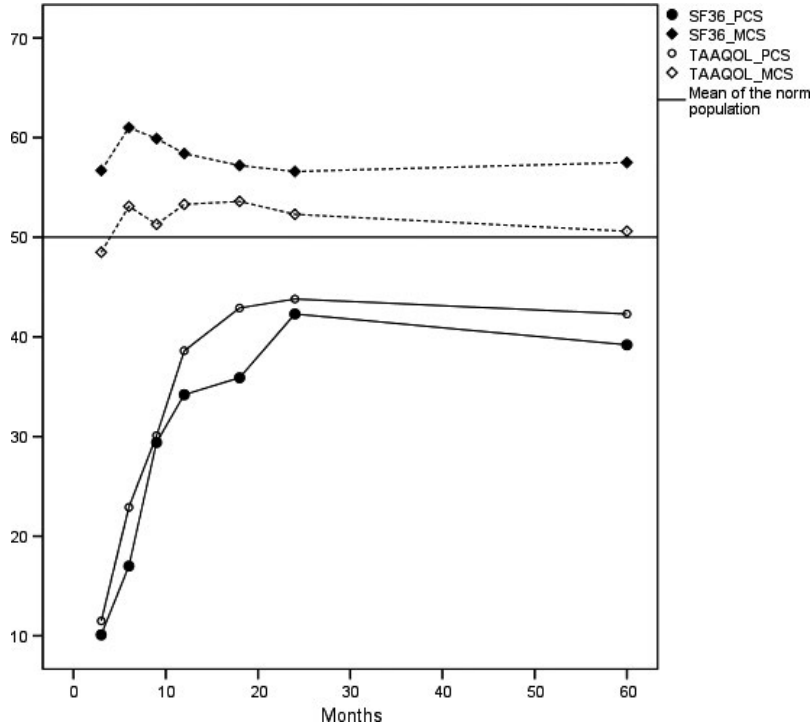

FIGURE 3 Estimated marginal mean scores of the Physical and Mental Component Summary Scores (PCS and MCS) of the SF-36 and TAAQOL during long-term follow-up

studies report advantages in favour of the ablative surgery patients and some in favour of the limb-salvage patients. However, these differences are small, limited to subscales of QoL measures and mostly not significant (Akahane et al., 2007; Aksnes et al., 2008; Bekkering, Vliet Vlieland, Fiocco, et al., 2012; Eiser et al., 2001; Ginsberg et al., 2007; Hopyan, Tan, Graham, \& Torode, 2006; Nagarajan et al., 2002; ZahltenHinguranage, Bernd, Ewerbeck, \& Sabo, 2004; Zahlten-Hinguranage, Bernd, \& Sabo, 2003). In this study, however, at two subscales: the PCS of the SF-36 and the cosmetic scale of the Bt-DUX, patients after ablative surgery scored significantly lower than after limb-salvage, indicating that patients after ablative surgery appear to be less content with the functional and cosmetic results of the surgery.

The course over time of QoL scores was comparable for both surgical intervention groups with only small and dissimilar differences at the different time points. These findings are in contradiction with our clinical experience and expert findings seeing a fast recovery and active lifestyle in ablative surgery patients and a longer rehabilitation and sedentary lifestyle in limb-salvage patients. However, as reported earlier, our study consists of a small number of patients.

As reported in the initial study; Physical QoL levels improved significantly during a 2 year follow-up after surgery. However, these improvements were mainly achieved in the first year after surgery and appeared to be small in the second year (Bekkering, Vliet Vlieland, Koopman, et al., 2012). With this extended study we aimed to determine if between the last evaluation at 2 years after surgery and this long-term follow-up evaluation further QoL improvements were achieved. During the reported interval, nearly all QoL scores appeared to have been declined. On the basis of these results, we could conclude that in children and adolescents after bone sarcoma surgery around the knee, no further improvements in QoL levels could be expected after 2 years. The results of previous studies on QoL after bone sarcoma surgery support this conclusion and report comparable
QoL scores at their evaluations with a longer follow-up duration (Eiser, 2009; Ginsberg et al., 2007; Hopyan et al., 2006; Koopman et al., 2005).

Despite functional disability, progressive disease and surgical reinterventions, our survivors after paediatric bone cancer are busy with work, study, relationships, and sometimes they have founded a family. Apparently, these functional constraints are no limitation to age appropriate social participation. It is therefore recommendable, to use in research among long-term primary bone cancer survivors a measure instrument within the World Health Organization classification domain participation; such as the Reintegration into Normal Living (RNL) index (Nagarajan et al., 2003). Furthermore, since malignant bone tumours patients after a follow-up of 5 years from surgery still score significantly lower on the physical QoL aspects than healthy peers, it's interesting to know if by intensive or specific training programs better outcome could be achieved.

The small number and young age of the survivors in our study limit the generalisability of the results. Therefore, prospective studies with a larger cohort of bone tumour patients with a wider age range are needed. However, despite these limitations this study is the first to prospectively examine QoL of survivors of childhood or adolescent malignant bone cancer and included a long-term prospective design.

In conclusion, at long-term follow-up, no further QoL improvements were achieved in comparison with the 2 years follow-up. Course and outcome of QoL scores after the different surgical interventions were generally comparable, however, they were significantly inferior for patients after ablative surgery at the physical (SF-36) and cosmetic domains.

\section{ACKNOWLEDGEMENTS}

This publication was made possible by grants from the Johanna Children Fund (Project no. 2003/0111-161), Children Fund Adrian Foundation (project no. 2003/0111) and BIO-Children Rehabilitation Fund (2003/0131-161).

\section{CONFLICT OF INTEREST}

The authors of the manuscript have no financial or personal relationships with other persons or organisations that could inappropriately influence (bias) his or her actions.

\section{REFERENCES}

Aaronson, N. K., Muller, M., Cohen, P. D., Essink-Bot, M. L., Fekkes, M., Sanderman, R., ... Verrips, E. (1998). Translation, validation, and norming of the Dutch language version of the SF-36 Health Survey in community and chronic disease populations. Journal of Clinical Epidemiology, 51, 1055-1068.

Abed, R., \& Grimer, R. (2010). Surgical modalities in the treatment of bone sarcoma in children. Cancer Treatment Reviews, 36, 342-347.

Akahane, T., Shimizu, T., Isobe, K., Yoshimura, Y., Fujioka, F., \& Kato, H. (2007). Evaluation of postoperative general quality of life for patients with osteosarcoma around the knee joint. Journal of Pediatric Orthopedics Part B, 16, 269-272. 
Aksnes, L. H., Bauer, H. C., Jebsen, N. L., Folleras, G., Allert, C., Haugen, G. S., \& Hall, K. S. (2008). Limb-sparing surgery preserves more function than amputation: A Scandinavian sarcoma group study of 118 patients. Journal of Bone and Joint Surgery. British Volume, 90, 786-794.

Bacci, G., Longhi, A., Versari, M., Mercuri, M., Briccoli, A., \& Picci, P. (2006). Prognostic factors for osteosarcoma of the extremity treated with neoadjuvant chemotherapy: 15 -year experience in 789 patients treated at a single institution. Cancer, 106, 1154-1161.

Bekkering, W. P., Billing, L., Grimer, R. J., Vlieland, T. P., Koopman, H. M., Nelissen, R. G., \& Taminiau, A. H. (2013). Translation and preliminary validation of the English version of the DUX questionnaire for lower extremity bone tumor patients (Bt-DUX): A disease-specific measure for quality of life. Journal of Surgical Oncology, 107, 353-359.

Bekkering, W. P., Vlieland, T. P., Koopman, H. M., Schaap, G. R., Schreuder, H. W., Beishuizen, A., \& Taminiau, A. H. (2009). The Bt-DUX: Development of a subjective measure of health-related quality of life in patients who underwent surgery for lower extremity malignant bone tumor. Pediatric Blood and Cancer, 53, 348-355.

Bekkering, W. P., Vliet Vlieland, T. P., Fiocco, M., Koopman, H. M., Schoones, J. W., Nelissen, R. G., \& Taminiau, A. H. (2012). Quality of life, functional ability and physical activity after different surgical interventions for bone cancer of the leg: A systematic review. Surgical Oncology, 21, e39-e47.

Bekkering, W. P., Vliet Vlieland, T. P., Koopman, H. M., Schaap, G. R., Beishuizen, A., Anninga, J. K., ... \& Taminiau, A. H. (2012). A prospective study on quality of life and functional outcome in children and adolescents after malignant bone tumor surgery. Pediatric Blood Cancer, 58, 978-985.

Breetvelt, I. S., \& van Dam, F. S. (1991). Underreporting by cancer patients: The case of response-shift. Social Science and Medicine, 32, 981-987.

Capanna, R., Scoccianti, G., Frenos, F., Vilardi, A., Beltrami, G., \& Campanacci, D. A. (2015). What was the survival of megaprostheses in lower limb reconstructions after tumor resections? Clinical Orthopaedics and Related Research, 473, 820-830.

Damron, T. A., Ward, W. G., \& Stewart, A. (2007). Osteosarcoma, chondrosarcoma, and Ewing's sarcoma: National Cancer Data Base Report. Clinical Orthopaedics and Related Research, 459, 40-47.

Eiser, C. (2009). Assessment of health-related quality of life after bone cancer in young people: Easier said than done. European Journal of Cancer, 45, 1744-1747.

Eiser, C., Darlington, A. S., Stride, C. B., \& Grimer, R. (2001). Quality of life implications as a consequence of surgery: Limb salvage, primary and secondary amputation. Sarcoma, 5, 189-195.

Eiser, C., \& Grimer, R. J. (1999). Quality of life in survivors of a primary bone tumour: A systematic review. Sarcoma, 3, 183-190.

Frances, J. M., Morris, C. D., Arkader, A., Nikolic, Z. G., \& Healey, J. H. (2007). What is quality of life in children with bone sarcoma? Clinical Orthopaedics and Related Research, 459, 34-39.

Ginsberg, J. P., Rai, S. N., Carlson, C. A., Meadows, A. T., Hinds, P. S., Spearing, E. M., ... Marchese, V. G. (2007). A comparative analysis of functional outcomes in adolescents and young adults with lower-extremity bone sarcoma. Pediatric Blood and Cancer, 49, 964-969.

Grimer, R. J. (2005). Surgical options for children with osteosarcoma. Lancet Oncology, 6, 85-92.

Hagleitner, M. M., Hoogerbrugge, P. M., van der Graaf, W. T., Flucke, U., Schreuder, H. W., \& te Loo, D. M. (2011). Age as prognostic factor in patients with osteosarcoma. Bone, 49, 1173-1177.

Han, G., Wang, Y., \& Bi, W. Z. (2012). Study on the health-related quality of life in patients after surgery for malignant bone tumors. Asian Pacific Journal of Cancer Prevention, 13, 127-130.

Henderson, E. R., O'Connor, M. I., Ruggieri, P., Windhager, R., Funovics, P. T., Gibbons, C. L., ... \& Letson, G. D. (2014). Classification of failure of limb salvage after reconstructive surgery for bone tumours: A modified system including biological and expandable reconstructions. Bone and Joint Journal, 96-b, 1436-1440.
Hinds, P. S., Gattuso, J. S., Billups, C. A., West, N. K., Wu, J., Rivera, C., ... \& Daw, N. C. (2009). Aggressive treatment of non-metastatic osteosarcoma improves health-related quality of life in children and adolescents. European Journal of Cancer, 45, 2007-2014.

Hoffman, R. D., Saltzman, C. L., \& Buckwalter, J. A. (2002). Outcome of lower extremity malignancy survivors treated with transfemoral amputation. Archives of Physical Medicine and Rehabilitation, 83, 177-182.

Hopyan, S., Tan, J. W., Graham, H. K., \& Torode, I. P. (2006). Function and upright time following limb salvage, amputation, and rotationplasty for pediatric sarcoma of bone. Journal of Pediatric Orthopedics, 26 , 405-408.

Jansen, S. J., Stiggelbout, A. M., Nooij, M. A., Noordijk, E. M., \& Kievit, J. (2000). Response shift in quality of life measurement in early-stage breast cancer patients undergoing radiotherapy. Quality of Life Research, 9, 603-615.

Kamphuis, M., Ottenkamp, J., Vliegen, H. W., Vogels, T., Zwinderman, K. H., Kamphuis, R. P., \& Verloove-Vanhorick, S. P. (2002). Health related quality of life and health status in adult survivors with previously operated complex congenital heart disease. Heart, 87, 356-362.

Koopman, H. M., Koetsier, J. A., Taminiau, A. H., Hijnen, K. E., Bresters, D., \& Egeler, R. M. (2005). Health-related quality of life and coping strategies of children after treatment of a malignant bone tumor: A 5-year follow-up study. Pediatric Blood and Cancer, 45, 694-699.

Liu, Y., Hu, A., Zhang, M., Shi, C., Zhang, X., \& Zhang, J. (2014). Correlation between functional status and quality of life after surgery in patients with primary malignant bone tumor of the lower extremities. Orthopaedic Nursing, 33, 163-170.

Maurice-Stam, H., Grootenhuis, M. A., Caron, H. N., \& Last, B. F. (2007) Course of life of survivors of childhood cancer is related to quality of life in young adulthood. Journal of Psychosocial Oncology, 25, 43-58.

Maurice-Stam, H., Oort, F. J., Last, B. F., Brons, P. P., Caron, H. N., \& Grootenhuis, M. A. (2008). Longitudinal assessment of health-related quality of life in preschool children with non-CNS cancer after the end of successful treatment. Pediatric Blood and Cancer, 50, 1047-1051.

Nagarajan, R., Neglia, J. P., Clohisy, D. R., \& Robison, L. L. (2002). Limb salvage and amputation in survivors of pediatric lower-extremity bone tumors: What are the long-term implications? Journal of Clinical Oncology, 20, 4493-4501.

Nagarajan, R., Neglia, J. P., Clohisy, D. R., Yasui, Y., Greenberg, M., Hudson, M., ... \& Robison, L. L. (2003). Education, employment, insurance, and marital status among 694 survivors of pediatric lower extremity bone tumors: A report from the childhood cancer survivor study. Cancer, 97, 2554-2564.

Pala, E., Henderson, E. R., Calabro, T., Angelini, A., Abati, C. N., Trovarelli, G., \& Ruggieri, P. (2013). Survival of current production tumor endoprostheses: Complications, functional results, and a comparative statistical analysis. Journal of Surgical Oncology, 108, 403-408.

Rodl, R., Pohlmann, U., Gosheger, G., Hoffmann, C., Leidinger, B., Lindner, N., \& Winkelmann, W. (2001). Ablative and extremity salvage tumor surgery of the lower extremity - A 10 year comparison]. Zeitschrift fur Orthopadie und Ihre Grenzgebiete, 139, 183-188.

Steliarova-Foucher, E., Stiller, C., Kaatsch, P., Berrino, F., Coebergh, J. W., Lacour, B., \& Parkin, M. (2004). Geographical patterns and time trends of cancer incidence and survival among children and adolescents in Europe since the 1970s (the ACCISproject): An epidemiological study. Lancet, 364, 2097-2105.

Stiller, C. A., Bielack, S. S., Jundt, G., \& Steliarova-Foucher, E. (2006). Bone tumours in European children and adolescents, 1978-1997. Report from the Automated Childhood Cancer Information System project. European Journal of Cancer, 42, 2124-2135.

Veenstra, K. M., Sprangers, M. A., van der Eyken, J. W., \& Taminiau, A. H. (2000). Quality of life in survivors with a Van Ness-Borggreve rotationplasty after bone tumour resection. Journal of Surgical Oncology, 73, 192-197.

Verrips, G. H., Vogels, A. G., den Ouden, A. L., Paneth, N., \& VerlooveVanhorick, S. P. (2000). Measuring health-related quality of life in 
adolescents: Agreement between raters and between methods of administration. Child: Care, Health and Development, 26, 457-469.

Vogels, T., Verrips, G. H., Verloove-Vanhorick, S. P., Fekkes, M., Kamphuis, R. P., Koopman, H. M., ... \& Wit, J. M. (1998). Measuring health-related quality of life in children: The development of the TACQOL parent form. Quality of Life Research, 7, 457-465.

Wafa, H., \& Grimer, R. J. (2006). Surgical options and outcomes in bone sarcoma. Expert Review of Anticancer Therapy, 6, 239-248.

Ware, J. E. Jr, Gandek, B., Kosinski, M., Aaronson, N. K., Apolone, G., Brazier,J.,...\&Thunedborg, K.(1998). The equivalence ofSF-36summary health scores estimated using standard and country-specific algorithms in 10 countries: Results from the IQOLA Project. International Quality of Life Assessment. Journal of Clinical Epidemiology, 51, 1167-1170.

Ware, J. E. Jr, Kosinski, M., Bayliss, M. S., McHorney, C. A., Rogers, W. H., \& Raczek, A. (1995). Comparison of methods for the scoring and statistical analysis of SF-36 health profile and summary measures:
Summary of results from the Medical Outcomes Study. Medical Care, 33, AS264-AS279.

Zahlten-Hinguranage, A., Bernd, L., Ewerbeck, V., \& Sabo, D. (2004). Equal quality of life after limb-sparing or ablative surgery for lower extremity sarcomas. British Journal of Cancer, 91, 1012-1014.

Zahlten-Hinguranage, A., Bernd, L., \& Sabo, D. (2003). Amputation or limb salvage? Assessing quality of life after tumor operations of the lower extremity. Orthopade, 32, 1020-1027.

How to cite this article: Bekkering, W. P., van Egmond-van Dam, J. C., Bramer, J. A. M., Beishuizen, A., Fiocco, M. and Dijkstra, P. D. S. (2016), Quality of life after bone sarcoma surgery around the knee: A long-term follow-up study. European Journal of Cancer Care, 00: 1-9. doi: 10.1111/ecc.12603 